\title{
S-allylcysteine suppresses ovarian cancer cell proliferation by DNA methylation through DNMT1
}

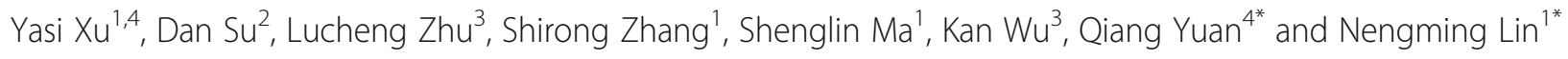

\begin{abstract}
Background: The anti-tumor effects of S-allylcysteine (SAC), a water-soluble garlic derivative, on human ovarian cancer cells have been previous studied in vitro and in vivo models but the precise epigenetic molecular mechanisms are still unclear. This study aimed to investigate the epigenetic mechanism of SAC.

Methods: Human epithelial ovarian cancer cell line A2780 was selected. Cell proliferation and cell cycle was analyzed. DNA methylation, DNA methyltransferase (DNMT) activity, tumor suppressor gene expressions, as well as protein expression were analyzed.

Results: SAC could inhibit the proliferation of A2780 cells in dose- and time-dependent manners (the IC 50 was 16 . $25 \mathrm{mmol} / \mathrm{L}$ and $5.25 \mathrm{mmol} / \mathrm{L}$ at $48 \mathrm{~h}$ and $72 \mathrm{~h}$ ). Treatment of A2780 cells with SAC resulted in G1/S phase arrest. SAC treatment decreased global DNA methylation levels in A2780 cells in a dose-dependent manner. SAC decreased the levels of 5-methylcytosine, DNMT activity, messenger RNA (mRNA) and protein levels of DNMT1. Additionally, SAC treatment resulted in re-expression of the mRNA and proteins of silenced tumor suppressor gene CDKN1A accompany with reduced cell division control 2 expression.
\end{abstract}

Conclusion: Our data indicated the potential therapeutic effects of SAC on the human ovarian carcinoma cell line A2780 in vitro. The epigenetic mechanism of action of SAC may have important implications for epigenetic therapy.

Keywords: Epigenetic, DNA methylation, S-allylcysteine, Ovarian cancer

\section{Background}

For many decades, ovarian cancer has been the most common gynecologic cancer and the leading cause of cancer death worldwide [1, 2]. The prognosis of most ovarian cancer patients remains poor even after surgery and paclitaxel/platinum-based chemotherapy. This is mainly caused by drug resistance, cancer metastasis, high cancer heterogeneity, and rapid tumor progression, etc.[3, 4] Therefore, continued development of novel anticancer drugs for ovarian cancer is urgently required.

Natural compounds derived from food have been investigated as new sources of anticancer drugs [5].

\footnotetext{
*Correspondence: 794884530@qq.com; Inm1013@163.com

${ }^{4}$ College of Pharmaceutical Science, Zhejiang Chinese Medical University, No.548 Binwen Road, Binjiang District, Hangzhou 310053, China

${ }^{1}$ Hangzhou Translational Medicine Research Center, Zhejiang Chinese

Medical University, Hangzhou First People's Hospital, No.261 Huansha Road,

Shangcheng District, Hangzhou 310006, China

Full list of author information is available at the end of the article
}

These agents act in a manner similar to the conventional anticancer drugs by disrupting the cell cycle or inducing apoptosis. Garlic (Allium sativum L.) is an edible crop with a wide range of traditional uses in treating different ailments including cancer, diabetes, and cardiovascular diseases.[6] Large-scale epidemiological studies within the past few decades have suggested a correlation between garlic consumption and a reduced incidence of cancer.[7, 8] Further investigation showed that organosulfur compounds naturally found in garlic are likely to be responsible for the decreased cancer risk.[9] $S$-allylcysteine, a water-soluble compound derived from garlic,[10] has been demonstrated its antitumor efficacy by inhibiting proliferation and inducing apoptosis in ovarian cancer cells [11].

Epigenetics focuses on those heritable changes which do not result from changes of DNA sequence. DNA methylation, which is the addition of a methyl group to 
a cytosine $(\mathrm{C})$ residue with the aid of an enzyme known as DNA methyltransferase (DNMT), is the most characterized epigenetic mechanism.[12, 13] Gene promoter hypermethylation has been recognized as an important mechanism by which tumor suppressor genes are shut down during development of tumors. It also has been reported that approximately half of the tumor suppressor genes are inactivated by epigenetic mechanisms rather than by genetic mechanisms in sporadic cancers. DNA methylation is commonly associated with increased levels or altered functions of DNMTs [14].

Our previous data demonstrated the potential therapeutic effects of SAC on the human ovarian carcinoma cell line A2780 in vitro [15]. SAC suppresses cell proliferation while simultaneously inducing apoptosis. In this study, we aimed to investigate the epigenetic mechanism contributing to antitumor efficacy by SAC.

\section{Methods}

Materials

Reangents were purchased as follows: RPMI-1640 medium and fetal bovine serum (FBS) (Thermo Scientific, South Logan, UT, USA), CCK-8 kits and Hoechst 33,258 (Sigma-Aldrich, St Louis, MO, USA), Giemsa solution (Solarbio, Beijing, China), BD BioCoat ${ }^{\text {tim }}$ BD Matrigel $^{\mathrm{mm}}$ Invasion Chambers, Cycletest Plus DNA Reagent and Annexin-V-Fluor Staining Kits (BD Biosciences, Franklin Lakes, NY, USA), Gentian violet (Huyu Biotech Co, Ltd., Shanghai, China), Cell Lysis Buffer (Cell signaling, Danvers, MA, USA), PVDF membrane (Millipore, Billerica, MA, USA), ECL Plus substrate (Thermo Scientific Pierce, Rockford, IL, USA), internal reference antibody against GADPH and primary antibodies against CDKN1A, cell division control 2 (CDC2), and p-CDC2 (Abcam Inc., Cambridge, MA, USA), 5-methylcytosine (5-mC) (Calbiochem, EMD Biosciences, SanDiego, CA), DNMT1, DNMT3a and DNMT3b (Imgenec Corporation, San Diego, CA), Methylamp ${ }^{\text {tw }}$ Global DNA Methylation Quantification Kit and EpiQuik DNMT Activity Assay Kit (Epigentek, New York, NY), Standardized real-time polymerase chain reaction (PCR) primers for DNMT1, DNMT3a, DNMT3b, and CDKN1A (SuperArray Biosciences, Fredrick, MD).

\section{Preparation of SAC}

SAC was purchased from Shanghai Fundamental Industrial Co, Ltd. (Shanghai, China). A $500 \mathrm{mmol} / \mathrm{L}$ stock solution of SAC was freshly prepared in phosphatebuffered saline (PBS) according to the manufacturer's instructions and was diluted accordingly as needed.

\section{Cell culture}

The human epithelial ovarian cancer cell line A2780 was kindly provided by the Zhejiang Cancer Hospital. The cells were cultured in RPMI-1640 medium supplemented with $10 \% \mathrm{FBS}$ and $1 \%$ penicillin/streptomycin in a $37^{\circ} \mathrm{C}$ incubator supplied with $5 \% \mathrm{CO} 2$.

\section{Cell count Kit-8 (CCK-8) assay}

Cells were seeded at a density of 5000 cells per well in 96-well plates in $100 \mu \mathrm{L}$ of medium and were incubated for $48 \mathrm{~h}$ before treatment. The cells were treated with different concentrations of SAC for 1,2 , or $3 \mathrm{~d}$. The medium was then removed, and $200 \mu \mathrm{L}$ of fresh medium containing 5\% CCK-8 was added for a further $1.5 \mathrm{~h}$. The color intensity was measured using a Multiskan Spectrum spectrophotometer (Thermo Scientific, Rockford, IL, USA) at $450 \mathrm{~nm}$. Each experiment consisted of eight replicates, and at least three individual experiments were performed.

\section{Cell cycle analysis}

A2780 cells $\left(3 \times 10^{5}\right)$ were cultured in 6-well plates for $48 \mathrm{~h}$ prior to the experiments. The cells were treated with different concentrations of SAC, ranging from 0 to $10 \mathrm{mmol} / \mathrm{L}$, for $24 \mathrm{~h}$. The cells were trypsinized and fixed with $75 \%$ ice-cold ethanol for several hours and then stained with the Cycletest Plus DNA Reagent Kit according to the manufacturer's instructions. The DNA content of 10,000 cells was analyzed by flow cytometry for each experiment (FACSCalibur, Becton Dickinson, Franklin Lakes, NJ, USA). Each experiment was analyzed in duplicate, and at least three independent experiments were performed.

\section{Global DNA methylation assay}

The total genomic DNA was extracted from the cells, which were treated with SAC or 5-aza-dc using the Qiagen $a m p^{R}$ DNA Mini Kit (Qiagen Sciences, Maryland, MD) following the manufacturer's instructions. The Global DNA methylation levels were determined using the Methylamp ${ }^{\text {ma }}$ Global DNA Methylation Quantification Kit according to the manufacturer's instructions. This analysis provides the levels of global DNA methylation, and is not specific to any particular gene. The methylated fraction of DNA is recognized by a 5 -mC antibody. With this colorimetric kit, the amount of methylated DNA, which is proportional to the optical density intensity, is quantified through an enzyme-linked immunosorbent assay-like reaction.

\section{5-mC immunostaining}

Cells were treated with various concentrations of SAC $(0,5,10,20$ and $30 \mathrm{mmol} / \mathrm{L})$ for $72 \mathrm{~h}$ and then harvested. A total of $1 \times 10^{5}$ to $2 \times 10^{5}$ cells were cytospun using a Cytospin 4 Equipment (Thermo Electron Corporation, Waltham, MA) at 1500 r.p.m. for $15 \mathrm{~min}$ and then processed for 5-mC cytostaining. Briefly, cells 
were permeabilized with $0.2 \%$ Triton X-100 in phosphatebuffered saline (PBS), washed with PBS for $10 \mathrm{~min}$. The cells were then blocked with $3 \%$ preimmune goat serum in PBS for $30 \mathrm{~min}$, followed by incubation with $3 \% \mathrm{H}_{2} \mathrm{O}_{2}$ for 20 min to quench endogenous peroxidase. After washing the cells with PBS, cells were incubated with 5-mC-specific antibody (1:500, vol/vol; Calbiochem, Gibbstown, NJ) for $2 \mathrm{~h}$, followed by sequential incubation of cells with biotinylated goat anti-mouse IgG1 and horseradish peroxidase-conjugated streptavidin and finally with diaminobenzidine substrate and counterstaining with methylene blue.

\section{DNMT activity assay}

A2780 cells were treated for $72 \mathrm{~h}$ with various concentrations of SAC. After desired time point, cells were harvested and nuclear extracts were prepared from various treatment groups using Epiquik Nuclear Extraction Kit (Epigentek) following the manufacturer's instructions. DNMT activity was determined using Epiquik DNMT Activity Assay Kit (Epigentek) according to the manufacturer's protocol.

\section{Quantitative mRNA analysis of DNMTs and tumor suppressor gene CDKN1A using RT-PCR}

Total RNA was extracted from the cells in different treatment groups using Trizol Reagents Kit (Invitrogen) and complementary DNA was synthesized through the reverse transcription reaction (iScript complementary DNA Synthesis Kit; Bio-Rad Laboratories). Using SYBR Green/Fluorescein PCR Master Mix, complementary DNA was amplified using real-time PCR with a Bio-Rad MyiQ thermocycler and SYBR Green detection system (Bio-Rad Laboratories). Samples were run in duplicate to ensure amplification integrity. Manufacturer supplied standardized primer pairs were used to measure the following: DNMT1, DNMT3a, DNMT3b, and CDKN1A. The standard PCR conditions were: $95{ }^{\circ} \mathrm{C}$ for $15 \mathrm{~min}$ and then 40 cycles at $95{ }^{\circ} \mathrm{C}$ for $30 \mathrm{~s}, 55^{\circ} \mathrm{C}$ for $30 \mathrm{~s}$ and $72{ }^{\circ} \mathrm{C}$ for $30 \mathrm{~s}$, as recommended (SuperArray Bioscience Corporation, Frederick, MD). The mRNA expression levels of genes were normalized to the expression level of the housekeeping gene GADPH and relative to the average of all delta $\mathrm{Ct}$-values in each sample using the cycle threshold $(\mathrm{Ct})$ method.

\section{Cell lysates and western blotting}

Analysis of protein levels was performed using western blotting. Cell lysates from different treatment groups were prepared as described previously [14, 15]. Proteins (25-40 $\mu$ g protein) were electrophoresed on premade $10 \%$ Trisglycine gels (Invitrogen) and then transferred onto nitrocellulose membranes. After blocking in freshly prepared PBS containing 3\% non-fat dry milk at room temperature for $30 \mathrm{~min}$, the membranes were incubated with antibodies against DNMT1, DNMT3a and DNMT3b, CDKN1A, CDC2, pCDC2, and GADPH at $4^{\circ}$ $\mathrm{C}$ overnight followed by an anti-rabbit peroxidaseconjugated secondary antibody at 1:1000 dilution (Santa Cruz Biotechnology, Santa Cruz, CA). Protein bands were visualized on X-ray film using an enhanced chemiluminescence system (Amersham Life Science, Piscataway, NJ). Equal protein loading was verified using anti$\mathrm{b}$ actin antibody. Experiments were repeated three times, and thus three western blots were run in each experiment, and representative blot is shown in each case.

\section{Statistical analysis}

Statistical analyses and data visualization were performed using IBM SPSS version 22.0 (IBM SPSS, Inc., Chicago, IL, USA) and GraphPad Prism, Version 6.01 (GraphPad Software Inc., San Diego, CA, USA). A twotailed Student's t-test was used for analysis of continuous variables. $P<0.05$ was considered statistically significant.

\section{Results \\ SAC inhibits the proliferation of A2780 cells in a dose- and time-dependent manner}

A2780 cells were treated with increasing concentration of SAC and proliferation was assessed using CCK-8 assays. $12.5 \mathrm{mmol} / \mathrm{L}$ of SAC resulted in $29 \%$ growth inhibition and $50 \mathrm{mmol} / \mathrm{L}$ of SAC resulted in $69 \%$ growth inhibition after $24 \mathrm{~h}$ treatment (Fig. 1). The $\mathrm{IC}_{50}$ of SAC was $22.76 \mathrm{mmol} / \mathrm{L}$. The results showed a dosedependent anti-proliferative effect of SAC on A2780 cells. Next, we determined the inhibitory effects of SAC on A2780 cells at $48 \mathrm{~h}$ and $72 \mathrm{~h}$. The $\mathrm{IC}_{50}$ were 16. $25 \mathrm{mmol} / \mathrm{L}$ at $48 \mathrm{~h}$ and $5.15 \mathrm{mmol} / \mathrm{L}$ at $72 \mathrm{~h}$, respectively (Fig. 1). The $\mathrm{IC}_{50}$ decreased corresponding to prolonged time of SAC exposure.

SAC results in G0/G1 phase cell cycle arrest of A2780 cells After treatment with SAC at a concentration of $2.5 \mathrm{mmol} /$ $\mathrm{L}$, flow cytometry showed a small increase in the percentage of G0/G1 phase in A2780 cells. When the SAC concentration increased to 5 and $10 \mathrm{mmol} / \mathrm{L}$, higher percentage of G0/G1 phase was observed $(p<0.001)$. Besides, flow cytometry showed $2.5 \mathrm{mmol} / \mathrm{L}$ of SAC resulted in a small decrease in the percentage of G2/M phase in A2780 cells (Fig. 2). As the SAC concentration increased to 5 and $10 \mathrm{mmol} / \mathrm{L}$, almost none of these cells stayed in the G2/M phase. Cell cycle changes may have caused the marked reduction in A2780 proliferation described in the previous section.

\section{SAC reduces global DNA methylation in A2780 cells}

To determine the effect of SAC on global DNA methylation in human ovarian cancer cells. A2780 cells were 


\section{S-allylcysteine}

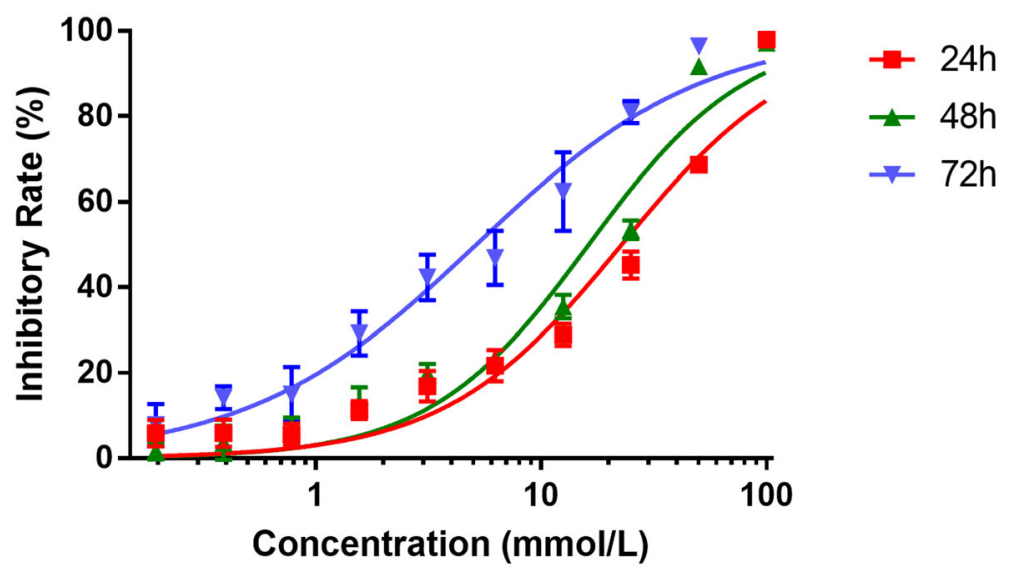

Fig. 1 The inhibitory effect of SAC on the proliferation of A2780 cells after 24,48 , and $72 \mathrm{~h}$ treatment. The $\mathrm{IC}_{50}$ were $22.76 \mathrm{mmol} / \mathrm{L}$, $16.25 \mathrm{mmol} /$ $L$, and $5.15 \mathrm{mmol} / \mathrm{L}$, respectively

treated with various concentration of SAC for $72 \mathrm{~h}$. Then cells were harvested and DNA was isolated for the analysis of global DNA methylation level. As shown in Fig. 3, treatment of cells with SAC resulted in a reduction in the levels of DNA methylation in a dosedependent manner. 5-Aza-dc is a potent DNA demethylation agent and used as a positive control.

\section{SAC induces DNA 5-mC demethylation in A2780 cells}

To examine the effect of SAC on DNA demethylation, A2780 cells were treated with SAC for $72 \mathrm{~h}$. Cells were harvested and immunocytostaining was performed to detect 5 mc-positive cells. Cells were also treated with 5 -aza-dc as a positive control. As shown in Fig. 4, SAC treatment decreased 5-mC-positive cells in a dose-dependent manner compared with non-SAC-treated A2780 cells $(P<0.001)$.
SAC and 5-aza-dc decrease DNMT activity, mRNA and protein expression of DNMTs in A2780 cells

As DNMTs play a crucial role in DNA methylation, we next determined the activity of DNMT in A2780 cells after treatment of cells with SAC for $72 \mathrm{~h}$. SAC decreased DNMT activity after treatment of cells in a dose-dependent manner $(P<0.001)$. The decrease in DNMT activity by SAC may be due to reduced expression of DNMT. These results were consistent with the quantitative analysis of the mRNA expression of the DNMTs using real-time PCR (Fig. 5b). The mRNA levels of DNMT1, DNMT3a and DNMT3b were significantly decreased $(P<0.001)$ in A2780 cells after the treatment of cells with SAC for $72 \mathrm{~h}$. There was also a decrease in the protein expression levels of DNMT1, but not DNMT3a and DNMT3b after the treatment of cells with SAC for $72 \mathrm{~h}$ compared with non-SAC-treated controls.

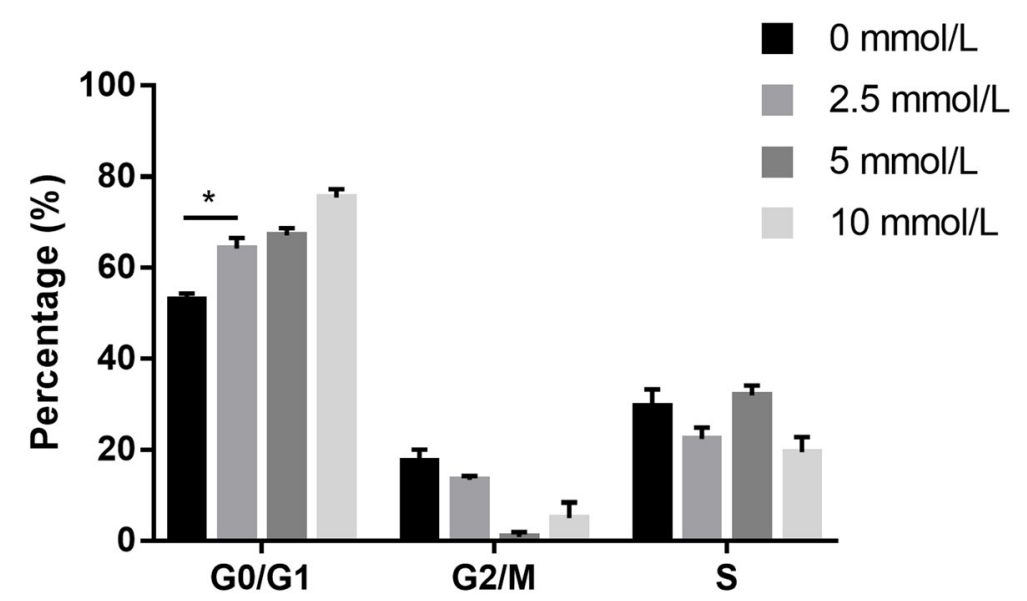

Fig. 2 Quantitative cell cycle analysis of A2780 cells in response to SAC treatment 


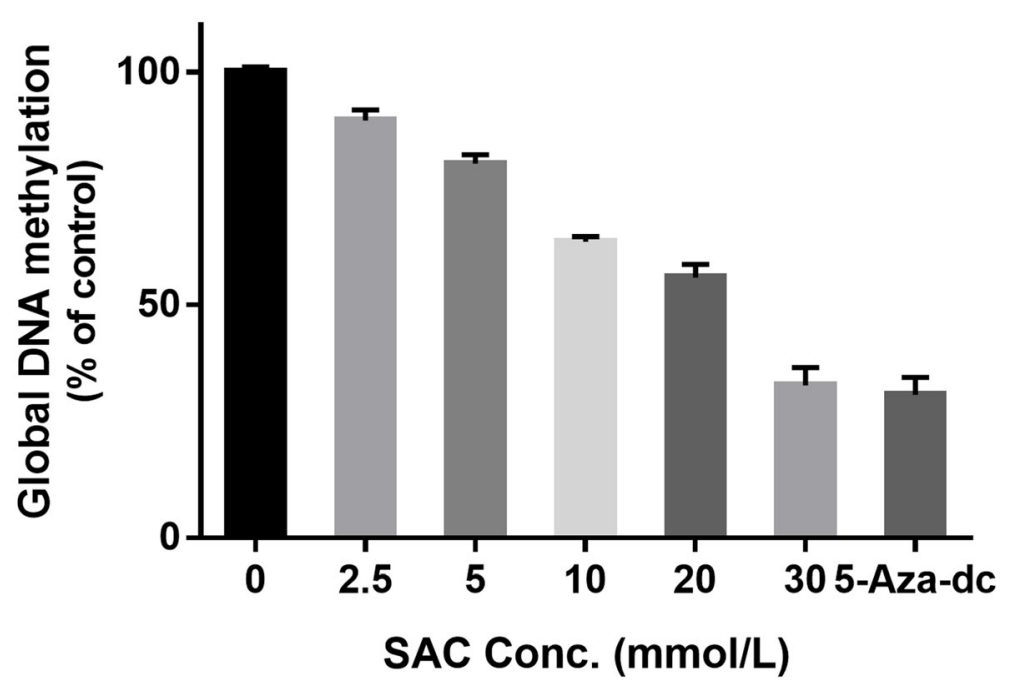

Fig. 3 Dose-dependent effect of SAC on the Global DNA methylation levels in A2780 cells. Cells were treated with SAC for $72 \mathrm{~h}$. Data are presented in terms of percent of control (non-SAC-treated) group, which was assigned a value of $100 \%$, and as means \pm SD, $n=3$

SAC and 5-aza-dc reactivate CDKN1A in A2780 cells

We further determined whether DNA demethylation after SAC treatment could reactivate tumor suppressor genes in A2780 cells. For this purpose, A2780 cells were treated with various concentrations of SAC and 5-aza-dc for $72 \mathrm{~h}$. Cellular RNA from different treatment groups was isolated and subjected to real-time PCR as detailed under Materials and Methods. As shown in Fig. 6a, RTPCR analysis showed that SAC treatment significantly increased mRNA levels of CDKN1A $(P<0.001)$ in a dose-dependent manner. 5-Aza-dc treatment also significantly increased the mRNA levels of CDKN1A. Similar to mRNA, protein levels were also determined using western blot (Fig. 6b). SAC treatment reactivated the silenced CDKN1A in a dose-dependent manner, and similar reactivation effect on tumor suppressor proteins was also observed when cells were treated with 5-aza-dc under same conditions. CDKN1A is a potent cyclindependent kinase inhibitor, then we detected the cyclindependent kinases. Western blot showed SAC downregulated $\mathrm{CDC} 2$ but upregulated p-CDC2.

\section{Discussion}

This study showed SAC dose-dependently inhibited the proliferation of human ovarian cancer A2780 cells and caused cell cycle arrest in G1/S phase. Epigenetic gene regulations have been recognized to play a crucial role in the etiology of cancer. DNA methylation is an

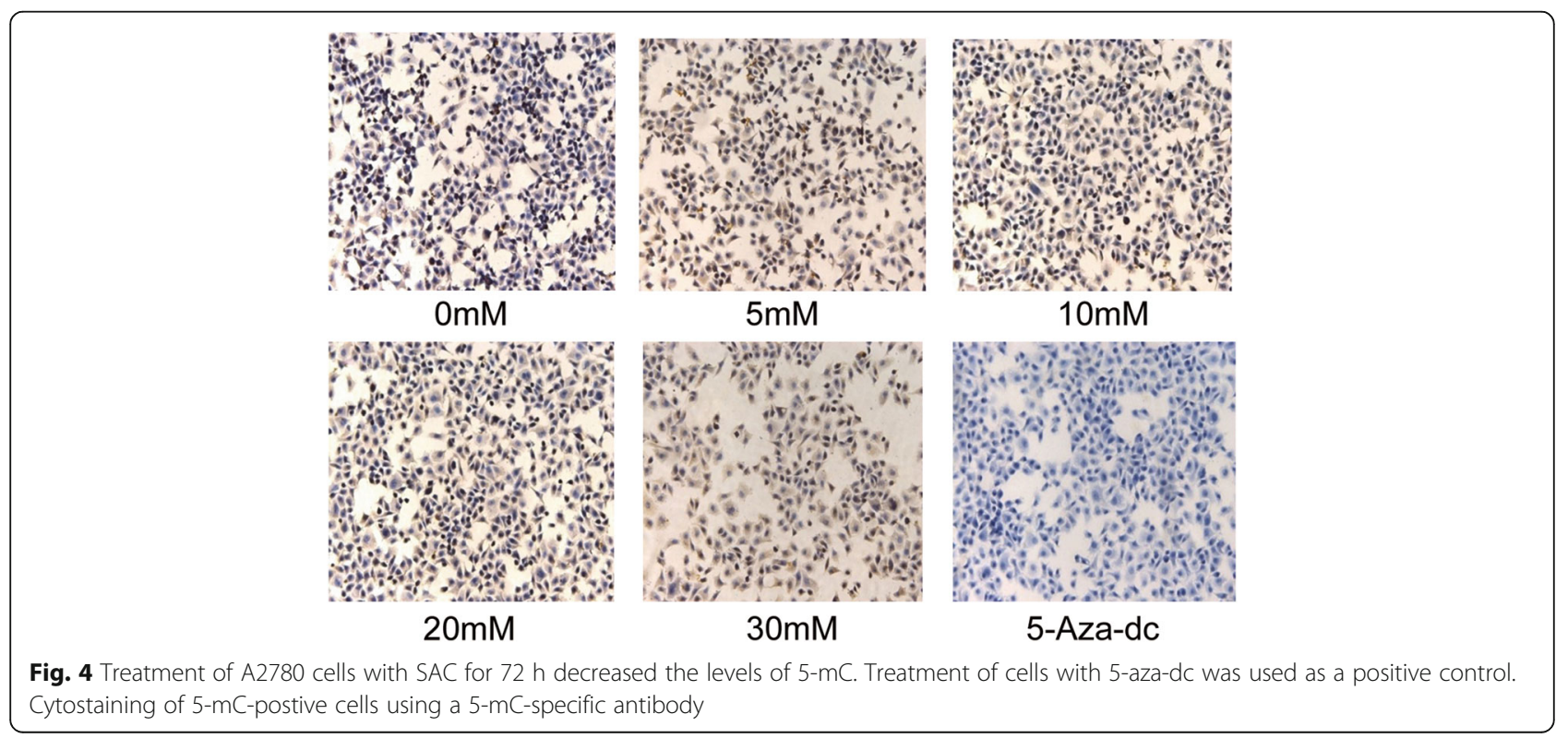



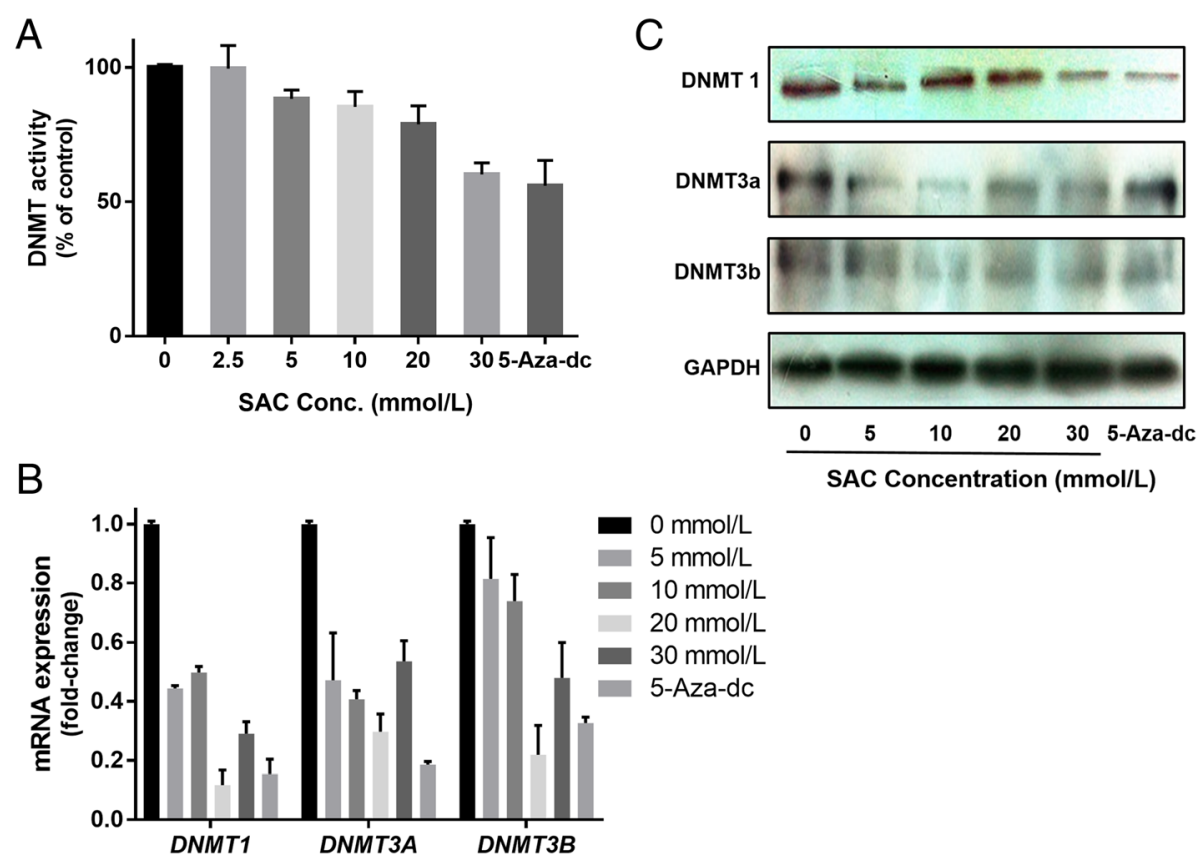

Fig. 5 Treatment of A2780 cells with SAC or 5-aza-dc for $72 \mathrm{~h}$ inhibits DNMT activity and decreases the levels of mRNA and protein expressions of DNMT1, DNMT3a and DNMT3b. a total DNMT activity in nuclear extracts was determined using the DNMT Activity Assay Kit. Data are presented in terms of percentage versus the results using non-SAC-treated controls, which was assigned a value of $100 \%$, and as means \pm SD; $n=3$. $\mathbf{b}$ Quantitative real-time PCR analysis of mRNA levels of DNMT1, DNMT3a and DNMT3b in cells. The results are presented as the expression of the individual mRNA with normalization to $\beta$-actin and as means $\pm S D, n=3$. c The levels of DNMT1, DNMT3a and DNMT3b in cell lysates were determined using western blot analysis after treating the cells with SAC for $72 \mathrm{~h}$. The treatment groups of 5 -aza-dc were used as controls

important epigenetic event in regulation of gene expression and maintenance of cellular function and that may contribute to cancer development $[6,7,10]$. Our data showed SAC decreased the levels of global DNA methylation and the expressions of DNMT1 but not DNMT3a/DNMT3b in A2780 cells. DNMT1 is a maintenance methylase, which is the most important in the whole process of DNA methylation, whereas DNMT3al DNMT3b is involved in de novo methylation [16]. Loo and his colleagues' work suggest the involvement of DNMT1 in the activation of cell cycle and DNA replication in diffuse large B-cell lymphoma cells [17]. In addition, Xiang et al. found silencing of DNMT1 led to cell cycle arrest and promotion of apoptosis in ovarian cancer cell lines [18]. These results indicated DNMT1 might have a correlation with cell cycle regulation. To validate this hypothesis, we determined cell cycle after different SAC exposure in A2780 cells. Similar with
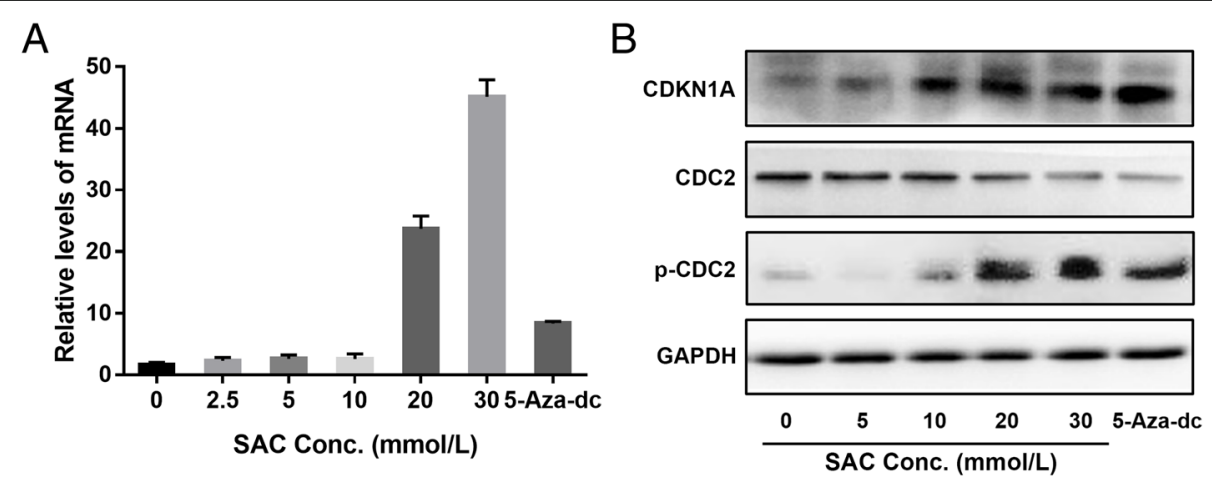

Fig. 6 Treatment of cells with SAC or 5-aza-dc for $72 \mathrm{~h}$ reactivates CDKN1A. a RNA was isolated from the cells of different treatment groups and subjected to the quantification of mRNA expression levels of by CDKN1A RT-PCR. Data were normalized to housekeeping gene (GAPDH) and are presented as relative change in mRNA levels in terms of mean \pm SD $(n=3)$. $\mathbf{b}$ The protein levels of CDKN1A, CDC2 and p-CDC2 were determined in cell lysates using western blotting under identical conditions 
previous work, our data showed SAC cause G1/S arrest in A2780 cells and decreased the expression of DNMT1.

The regulation of cell cycle progression is an important system to control cancer cell proliferation. The cell cycle is a complex process that ensures correct cell division. It is tightly regulated by arrest at the G1 or G2 checkpoints and multiple molecular pathways, including oncogenic signaling, cyclin-dependent kinases (CDKs), and their regulatory inhibitors [19]. CDK inhibitor CDKN1A induces growth arrest and inhibit cell proliferation by negatively regulating cell cycle checkpoints [20,21]. Several studies have showed CDKN1A could mediate $\mathrm{G} 1$ cell cycle arrest in cancer cells $[22,23]$. Our study also found SAC reactivates or reexpresses mRNA expression of tumor suppressor gene $C D K N 1 A$. As the concentration of SAC increase, more fraction of G1 cell cycle arrest and CDKN1A expression were observed. As CDKN1A is a CDK inhibitor, we further detected CDK expression. Our data confirmed the expression of $\mathrm{CDC} 2$ was negative correlated with CDKN1A. Interestingly, increased p-CDC2 was observed when A2780 cells were treated with SAC, this might be a cellular compensation act after cell cycle arrest.

Of course, this study had some limitations: detailed mechanisms regarding how SAC regulated cell cycle, how to combination with chemotherapy or radiotherapy, etc. But we hope our data can help the validation of $\mathrm{SAC}$ as a potential, potent anti-cancer drug candidate.

\section{Conclusion}

In summary, this study showed SAC could inhibit the proliferation of human ovarian cancer A2780 cells and caused cell cycle arrest in G1/S phase. SAC treatment decreased global DNA methylation levels and DNMT1 expression, and reactivated CDKN1A. These findings provide evidence for further understanding the anticancer mechanisms and clinical applications of SAC.

\section{Acknowledgements}

We thank Jianguo Feng for his work in manuscript revision.

\section{Funding}

This study was supported by grant from Zhejiang Traditional Chinese Medicine Research Project (2017ZA099).

\section{Availability of data and materials}

The main datasets supporting the conclusions of this article are included within the article.

\section{Authors' contributions}

YSX have been involved in drafting the article or revising it critically for important intellectual content. SLM and KW have made substantial contributions to acquisition of data. SRZ, ZLC, and NML have made substantial contributions to analysis and interpretation of data. QY and NML have made substantial contributions to conception and design of this manuscript and final approval of the version to be submitted. All authors read and approved the final manuscript.

Ethics approval and consent to participate Not applicable.

\section{Competing interests}

The authors declare that they have no competing interests.

\section{Publisher's Note}

Springer Nature remains neutral with regard to jurisdictional claims in published maps and institutional affiliations.

\section{Author details}

${ }^{1}$ Hangzhou Translational Medicine Research Center, Zhejiang Chinese Medical University, Hangzhou First People's Hospital, No.261 Huansha Road, Shangcheng District, Hangzhou 310006, China. ${ }^{2}$ Department of Pathology, Zhejiang Cancer Hospital, No.38, Guangji Road, Hangzhou 310022, China. ${ }^{3}$ Department of Oncology, Hangzhou Cancer Hospital, No.34, Yanguan Road, Hangzhou 310002, China. ${ }^{4}$ College of Pharmaceutical Science, Zhejiang Chinese Medical University, No.548 Binwen Road, Binjiang District, Hangzhou 310053, China.

Received: 30 January 2018 Accepted: 3 May 2018

Published online: 14 May 2018

\section{References}

1. Coburn SB, Bray F, Sherman ME, Trabert B. International patterns and trends in ovarian cancer incidence, overall and by histologic subtype. Int J Cancer. 2017:140:2451-60

2. Reid BM, Permuth JB, Sellers TA. Epidemiology of ovarian cancer: a review. Cancer Biol Med. 2017:14:9-32.

3. Yin F, Liu X, Li D, Wang Q, Zhang W, Li L. Tumor suppressor genes associated with drug resistance in ovarian cancer (review). Oncol Rep. 2013; 30:3-10.

4. Lengyel E. Ovarian cancer development and metastasis. Am J Pathol. 2010; 177:1053-64.

5. Nobili S, Lippi D, Witort E, et al. Natural compounds for cancer treatment and prevention. Pharmacol Res. 2009:59:365-78.

6. Bayan L, Koulivand PH, Gorji A. Garlic: a review of potential therapeutic effects. Avicenna J Phytomed. 2014:4:1-14.

7. Butt MS, Sultan MT, Butt MS, lqbal J. Garlic: nature's protection against physiological threats. Crit Rev Food Sci Nutr. 2009:49:538-51.

8. Zhou Y, Zhuang W, Hu W, Liu GJ, Wu TX, Wu XT. Consumption of large amounts of Allium vegetables reduces risk for gastric cancer in a metaanalysis. Gastroenterology. 2011;141:80-9.

9. Iciek M, Kwiecien I, Chwatko G, Sokolowska-Jezewicz M, Kowalczyk-Pachel D, Rokita $\mathrm{H}$. The effects of garlic-derived sulfur compounds on cell proliferation, caspase 3 activity, thiol levels and anaerobic sulfur metabolism in human hepatoblastoma HepG2 cells. Cell Biochem Funct. 2012; 30:198-204

10. Lai $\mathrm{KC}$, Kuo CL, Ho HC, et al. Diallyl sulfide, diallyl disulfide and diallyl trisulfide affect drug resistant gene expression in Colo 205 human colon cancer cells in vitro and in vivo. Phytomedicine. 2012:19:625-30.

11. Chu Q, Ling MT, Feng $H$, et al. A novel anticancer effect of garlic derivatives: inhibition of cancer cell invasion through restoration of E-cadherin expression. Carcinogenesis. 2006;27:2180-9.

12. Hegi ME, Sciuscio D, Murat A, Levivier M, Stupp R. Epigenetic deregulation of DNA repair and its potential for therapy. Clin Cancer Res. 2009; 15:5026-31.

13. Jones PA, Baylin SB. The fundamental role of epigenetic events in cancer. Nat Rev Genet. 2002;3:415-28.

14. Counts JL, Goodman Jl. Alterations in DNA methylation may play a variety of roles in carcinogenesis. Cell. 1995;83:13-5.

15. Xu YS, Feng JG, Zhang D, et al. S-allylcysteine, a garlic derivative, suppresses proliferation and induces apoptosis in human ovarian cancer cells in vitro. Acta Pharmacol Sin. 2014;35:267-74.

16. Dan J, Chen T. Genetic studies on mammalian DNA methyltransferases. Adv Exp Med Biol. 2016;945:123-50.

17. Loo SK, Ab Hamid SS, Musa M, Wong KK. DNMT1 is associated with cell cycle and DNA replication gene sets in diffuse large B-cell lymphoma. Pathol Res Pract. 2018;214(1):134-43.

18. Xiang $\mathrm{Y}, \mathrm{Ma} \mathrm{N}$, Wang D, et al. MiR-152 and miR-185 co-contribute to ovarian cancer cells cisplatin sensitivity by targeting DNMT1 directly: a novel epigenetic therapy independent of decitabine. Oncogene. 2014;33:378-86.

19. Lapenna S, Giordano A. Cell cycle kinases as therapeutic targets for cancer. Nat Rev Drug Discov. 2009;8:547-66. 
20. Gartel AL, Tyner AL. The role of the cyclin-dependent kinase inhibitor p21 in apoptosis. Mol Cancer Ther. 2002;1:639-49.

21. Senderowicz AM. Small-molecule cyclin-dependent kinase modulators. Oncogene. 2003;22:6609-20.

22. Jeong YJ, Hoe HS, Cho HJ, et al. Suppression of c-Myc enhances p21(WAF1/ CIP1) -mediated G1 cell cycle arrest through the modulation of ERK phosphorylation by ascochlorin. J Cell Biochem. 2018;119:2036-47.

23. Kan WL, Yin C, Xu HX, et al. Antitumor effects of novel compound, guttiferone $\mathrm{K}$, on colon cancer by p21Waf1/Cip1-mediated G(0) /G(1) cell cycle arrest and apoptosis. Int J Cancer. 2013;132:707-16.

Ready to submit your research? Choose BMC and benefit from:

- fast, convenient online submission

- thorough peer review by experienced researchers in your field

- rapid publication on acceptance

- support for research data, including large and complex data types

- gold Open Access which fosters wider collaboration and increased citations

- maximum visibility for your research: over $100 \mathrm{M}$ website views per year 